Article

\title{
Depolarization Ratios of Methane Raman Bands as a Function of Pressure
}

\author{
Dmitry Petrov 1,2 \\ 1 Institute of Monitoring of Climatic and Ecological Systems, Siberian Branch of the Russian Academy of \\ Sciences, 634055 Tomsk, Russia; dpetrov@imces.ru \\ 2 Tomsk State University, 634050 Tomsk, Russia
}

Academic Editor: Xuefeng Wang

Received: 27 March 2020; Accepted: 20 April 2020; Published: 22 April 2020

check for

\begin{abstract}
In this work, we measured the intensities of Q-branches of the $v_{1}, v_{2}$ and $v_{3}$ bands in the polarized and depolarized methane Raman spectra in the pressure range of 1-60 atm. It was established that the pressure dependence of depolarization ratios of the $v_{2}$ and $v_{3}$ bands are negligible. In turn, the depolarization ratio of the $v_{1}$ band increases with increasing pressure and reaches approximately 0.0045 at $60 \mathrm{~atm}$. These data are more precise than previously published ones because $v_{1}$ band intensities were determined taking into account the contribution of overlapping lines of $v_{3}$ band. The presented data will be useful in calculating the methane polarizabilities at high pressure, as well as in calculating methane Raman spectra for measuring the natural gas composition using Raman spectroscopy.
\end{abstract}

Keywords: Raman spectroscopy; methane; depolarization ratio

\section{Introduction}

Methane is one of the most abundant molecules on Earth. It is present in atmospheric air, often found in inclusions in minerals, and is also the dominant component of natural gas. Development of Raman gas analysis [1-9] brings up the need of information that allows taking into account changes in the methane Raman spectrum under various conditions (temperature, pressure, environment). At present, shifts and broadenings of its fundamental bands [10-15], as well as changes in the ratio of peak intensities [13,15-17] are known. One of the important characteristics of the Raman bands, along with the position, half-width, and scattering cross-section, is the depolarization ratio $(\rho)$. This value characterizes the symmetry of the vibrations and is defined as the ratio $I_{\perp} / I_{\|}$, where $I_{\perp}$ and $I_{\|}$are the Raman intensities with orthogonal and parallel orientation of the polarization plane to the polarization plane of the exciting radiation, respectively. As a rule, the higher the symmetry, the lower the degree of depolarization. On the one hand, measuring the depolarization ratio makes it possible to detect intermolecular interactions that lead to distortion of the symmetry of the molecule [18,19]. On the other hand, the exact values of depolarization ratios obtained from the experiment can be used to verify the polarizabilities of the molecules, which, in turn, are the basis for calculating the line intensities.

It is known that in the methane Raman spectrum, the fundamental $v_{1}$ band (symmetric $\mathrm{C}-\mathrm{H}$ stretching mode, $2917 \mathrm{~cm}^{-1}$ ) is polarized, i.e., $\rho=0$, and $v_{2}$ (bending mode, $1534 \mathrm{~cm}^{-1}$ ), $v_{3}$ (asymmetric C-H stretching mode, $3020 \mathrm{~cm}^{-1}$ ), and $v_{4}$ (bending mode, $1306 \mathrm{~cm}^{-1}$ ) are depolarized bands, i.e., $\rho=0.75$ [20]. These data are correct for low pressure, when the molecules do not significantly affect each other. Rose et al. [21] and Wright et al. [22] showed that the depolarization ratio of $v_{1}$ in pure methane increases with pressure in the range of 1-1000 bar. The main disadvantage of these works is the low signal-to-noise ratio of the experimental setups used, and as a consequence, the high uncertainty of the measured values. The aim of this work is to obtain the depolarization ratios of both the $v_{1}$ band and the $v_{2}$ and $v_{3}$ bands in the pressure range of 1-60 atm using an experimental setup with higher sensitivity. 


\section{Experiment}

For research, a Raman spectrometer based on the 90 degree geometry of scattered light collection was used [1]. The gas cell represented a hollow metal cube with a volume of approximately $10 \mathrm{~cm}^{3}$ having three fused silica windows. A solid-state laser with a wavelength of $532 \mathrm{~nm}$ and a power of $1500 \mathrm{~mW}$ was used as an excitation source. To collect the scattered light, two f/1.8-lens objectives were used. A holographic notch-filter and a polarizer were installed between them. Rotation of the polarizer allowed us to register radiation with the desired polarization plane. To record Raman spectra, we used an f/1.8-spectrometer equipped with a Hamamatsu CCD array $(2048 \times 256$ pix $)$ with thermoelectric cooling to $-10{ }^{\circ} \mathrm{C}$. Using a diffraction grating of 1600 lines $/ \mathrm{mm}$ provides simultaneous record of spectrum in the range of $200-3800 \mathrm{~cm}^{-1}$ with a dispersion of approximately $1.8 \mathrm{~cm}^{-1} /$ pixel. Wavenumber calibration was performed using the emission spectrum of neon [23].

Raman spectra of methane were recorded on the equipment described above at pressures from 1 to $60 \mathrm{~atm}$ with a step of $5 \mathrm{~atm}$. For each pressure, polarized $\left(I_{\|}\right)$and depolarized $\left(I_{\perp}\right)$ spectra were recorded. The exposure time at a pressure of $1 \mathrm{~atm}$ was $500 \mathrm{~s}$, and for all other pressures it was $100 \mathrm{~s}$. The gas temperature and the air temperature in the laboratory during all experiments were maintained at a level of $298 \pm 1 \mathrm{~K}$. The change in gas pressure in the cell during the recording of two spectra with different polarizations was no more than $0.01 \mathrm{~atm}$ at a pressure of $1 \mathrm{~atm}$, and no more than $0.1 \mathrm{~atm}$ at a pressure of $60 \mathrm{~atm}$. The error of the pressure gauge used was less than $0.1 \%$.

\section{Results and Discussion}

Figure 1 shows the polarized and depolarized methane Raman spectra. It can be seen that only the $v_{2}, v_{3}$ and, in part, $2 v_{4}$ bands ( $F_{2}$ and $E$ symmetry species [24]) are present in the depolarized spectrum. To obtain the depolarization ratios, the integrated intensities of the Q-branches of $v_{1}, v_{2}$, and $v_{3}$ bands in each spectrum were obtained. The intensity of $v_{4}$ band was too weak to measure. Integration was carried out in the ranges of 2888-2938 $\mathrm{cm}^{-1}, 1515-1555 \mathrm{~cm}^{-1}$, and $2990-3040 \mathrm{~cm}^{-1}$ for the $v_{1}, v_{2}$ and $v_{3}$ bands, respectively. As shown in Figure 2, the pressure dependence of depolarization ratio of the $v_{2}$ and $v_{3}$ bands is negligible. In turn, the depolarization ratio of the $v_{1}$ band increases with pressure.

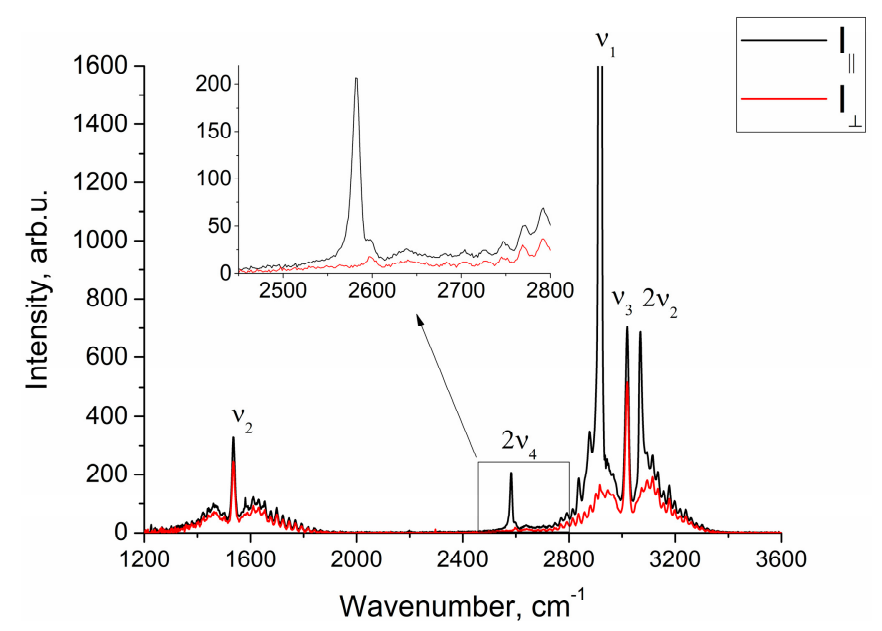

Figure 1. Polarized and depolarized methane Raman spectra at $P=50 \mathrm{~atm}$.

The error bars shown in Figure 2 were calculated as follows. We believe that in our case, the main source of the error in measuring $\rho$ is the signal fluctuations caused by shot noise and detector noise. To determine these fluctuations, we have additionally recorded five methane Raman spectra at pressures of 1 and $60 \mathrm{~atm}$. From the spectra obtained, standard deviations were estimated of the integral intensities $\delta_{P}$ in the specified spectral ranges for these pressures. For other pressure values, $\delta_{P}$ 
were estimated by interpolating these data. The errors in measuring the depolarization ratio at each $P$ $\left(\Delta_{P}\right)$ were estimated using Equation (1)

$$
\Delta_{P}=\frac{2 \delta_{P}}{I_{\| P}}
$$

where $I_{\|_{P}}$ is the integrated intensities in the polarized spectrum obtained at this pressure.
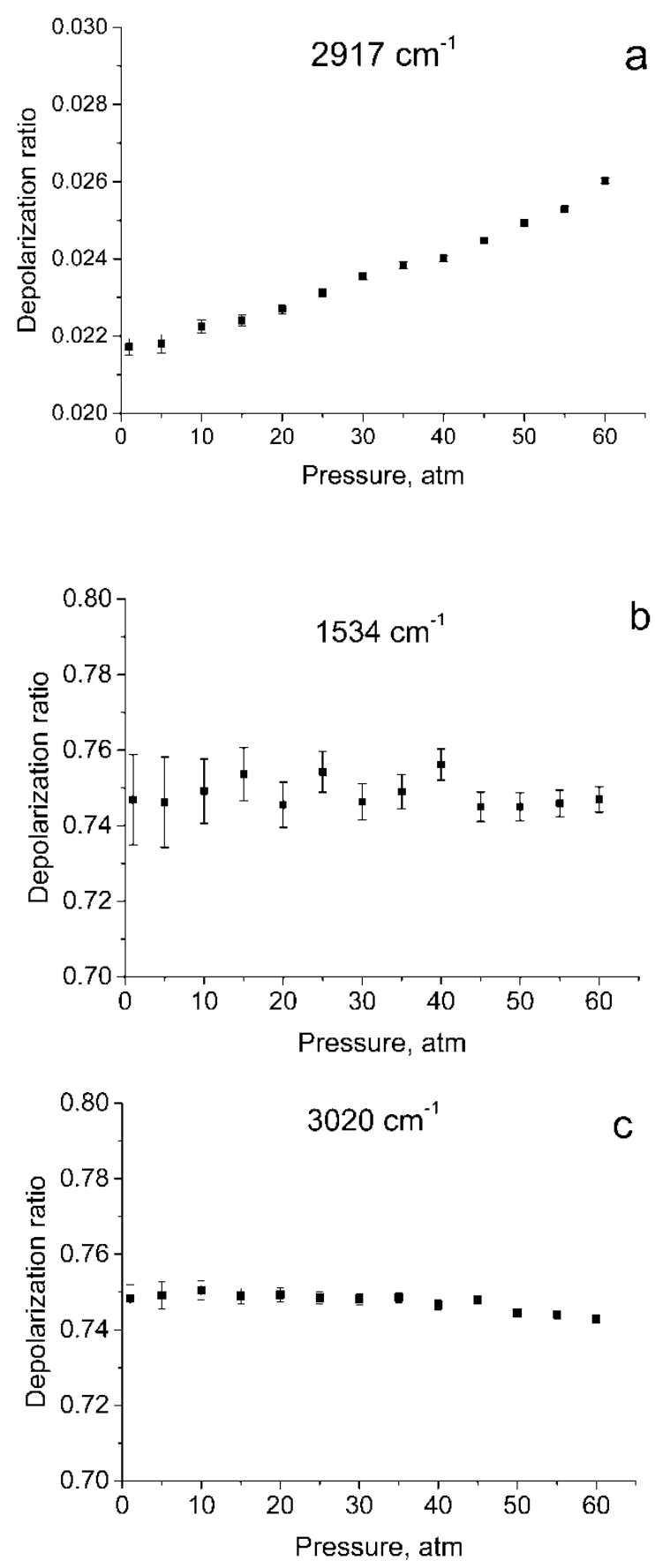

Figure 2. Depolarization ratios for $v_{1}(\mathbf{a}), v_{2}(\mathbf{b})$, and $v_{3}(\mathbf{c})$ bands as a function of pressure.

As seen from Figure 1, in the region of $2917 \mathrm{~cm}^{-1}$, the $v_{1}$ band overlaps with the lines of the O-branch of the $v_{3}$ band. This means that the obtained integrated intensities of $v_{1}$ band are somewhat different from the true ones. Therefore, the depolarization ratios for $v_{1}\left(\rho^{v_{1}}\right)$ shown in Figure 2a, have been calculated with an error and should be improved. 
An analysis of the depolarized spectra showed that the peak in the region of $2916-2917 \mathrm{~cm}^{-1}$ increases with pressure, as shown in Figure 3. This peak belongs to $v_{1}$ band. We estimated changes in the integrated intensities in the range of $2888-2938 \mathrm{~cm}^{-1}$ for polarized and depolarized spectra at different pressures. For this purpose, intensities at each pressure $\left(I_{P}\right)$ have been converted into intensities corresponding to the densities of molecules at $1 \mathrm{~atm}\left(I_{P}{ }^{\prime}\right)$ using Equation (2):

$$
I_{P}^{\prime}=\frac{I_{P}}{P / Z(P)}
$$

where $\mathbf{Z}(\boldsymbol{P})$ is the methane compressibility factor at $\mathrm{T}=298 \mathrm{~K}$, which is a function of pressure. The virial coefficients for calculating $\mathbf{Z}(\boldsymbol{P})$ were taken from [25].

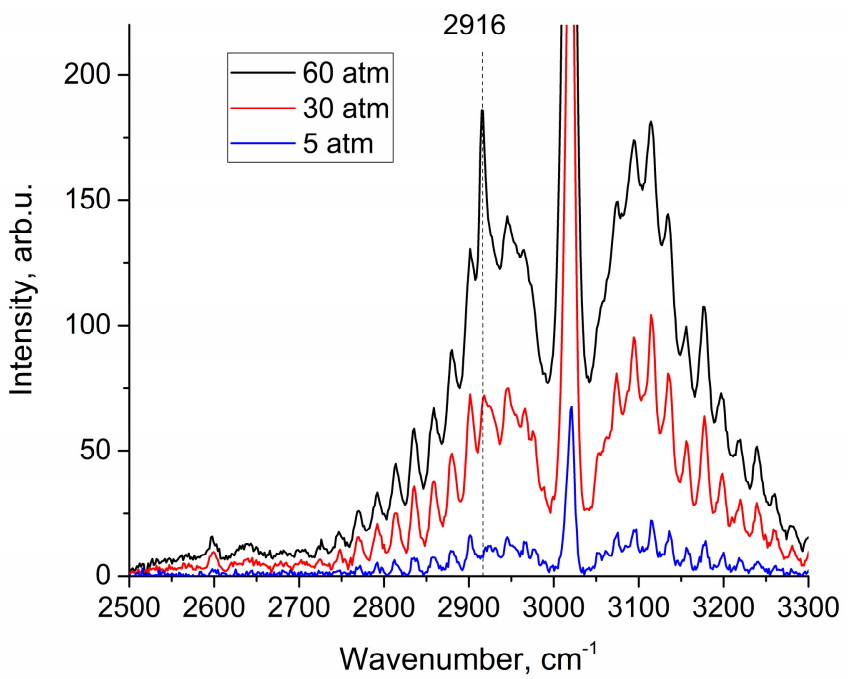

Figure 3. Depolarized methane Raman spectra at 5, 30, and 60 atm.

According to the data shown in Figure 4, both a decrease in intensity in the polarized spectrum and an increase in intensity in the depolarized spectrum are observed. This results from lower methane molecule symmetry at high pressure [21,22]. To verify the fact that the increase in the intensity in Figure $4 \mathrm{~b}$ is not due to the features of the experiment, Figure 5 shows the dependence of the integrated intensity of the depolarized spectrum of the $v_{3}$ band in the range of $2820-2870 \mathrm{~cm}^{-1}$ where there are no $v_{1}$ lines. Referring to this figure, the intensities after normalization per unit of density is stable. Thus, the data presented in Figure $4 \mathrm{~b}$ are correct. Note that, as shown in Figure 4 , the increase in intensity in the depolarized spectrum is less than its decrease in the polarized one. Taking into account that the intensity ratio of the $2 v_{4} / v_{1}$ and $2 v_{2} / v_{1}$ increases with increasing pressure [13], it can be assumed that the decrease in the $v_{1}$ intensity in the polarized spectrum is caused not only by intensity redistribution to the depolarized spectrum, but also to $2 v_{4}$ and $2 v_{2}$ overtones by means of Fermi resonance [24].

The data given in Figure $4 \mathrm{~b}$ are the sum of intensities of $v_{1}$ and $v_{3}$ bands. Thus, they can be represented using Equation (3):

$$
I_{\perp}^{v_{3}+v_{1}}(P)=I_{\perp}^{v_{3}}+I_{\perp}^{v_{1}}(P)
$$

where $I_{\perp}^{v_{1}}$ and $I_{\perp}^{v_{3}}$ are the intensities for the $v_{1}$ and $v_{3}$ bands in the depolarized spectrum, respectively. As seen from Figure 5, pressure dependence of $I_{\perp}^{v_{3}}$ is negligible. In addition, according to the calculations [26], at $\mathrm{P}=1 \mathrm{~atm}, \rho^{v_{1}}=0$, therefore, $I_{\perp}^{v_{3}}(1)=0$ and $I_{\perp}^{v_{3}+v_{1}}(1)=I_{\perp}^{v_{3}}$. Having this in mind, we calculated $I_{\perp}^{v_{1}}(P)$. The $\rho^{v_{1}}$ for various pressures were calculated using Equation (4).

$$
\rho^{v_{1}}=\frac{I_{\perp}^{v_{1}}}{I_{\|}-\frac{4}{3}\left(I_{\perp}-I_{\perp}^{v_{1}}\right)}
$$



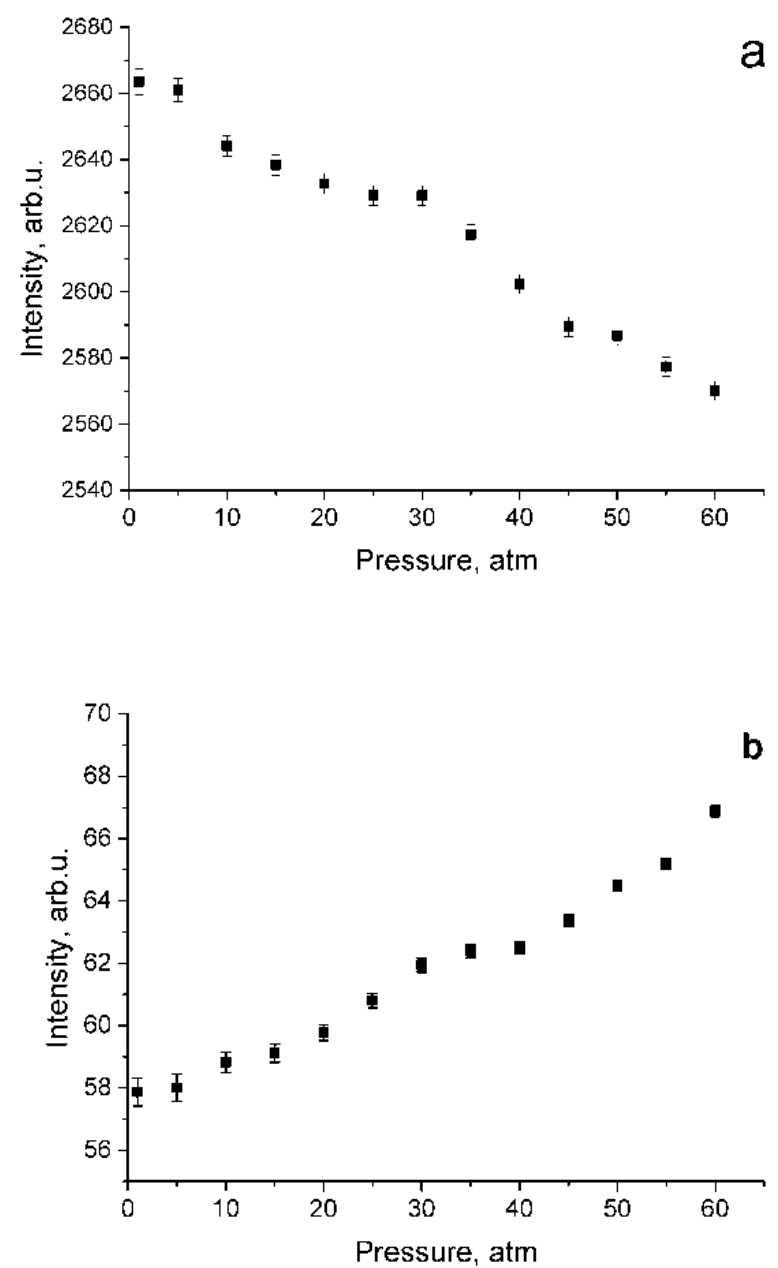

Figure 4. Pressure dependence of integrated intensities in the range of $2890-2940 \mathrm{~cm}^{-1}$ for polarized (a) and depolarized (b) methane spectra which were normalized using Equation (2).

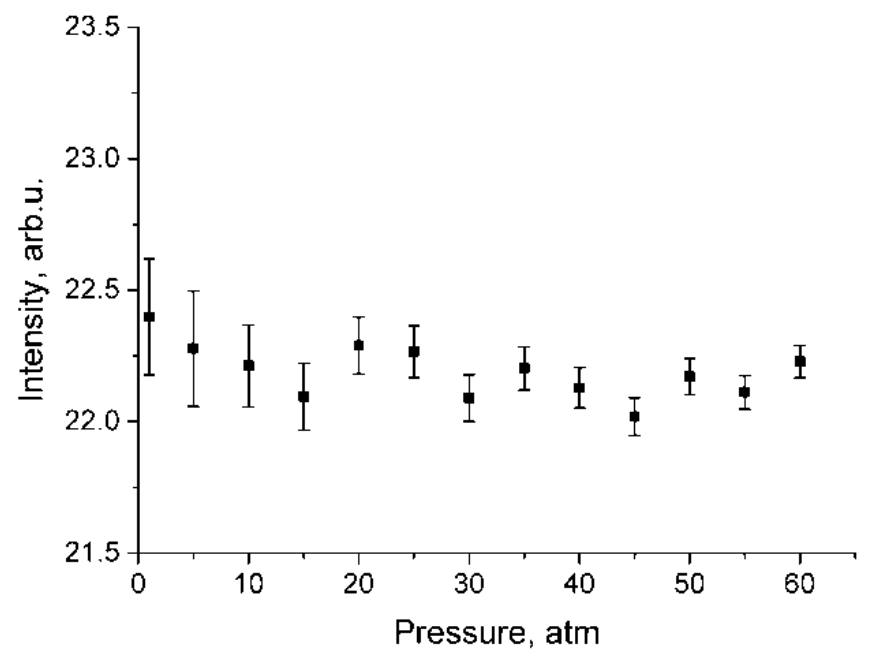

Figure 5. Pressure dependence of integrated intensities of $v_{3}$ band in the range of $2820-2870 \mathrm{~cm}^{-1}$ for depolarized methane spectra which were normalized using Equation (2).

As follows from Figure 6, the depolarization ratio increases significantly less compared to the data of Rose et al. [21]. In the studied pressure range, an increase in $\rho^{v_{1}}$ is close to a linear dependence. According to [21], $\rho^{v_{1}}$ increases with pressure up to approximately $1000 \mathrm{~atm}$. In practice, to analyze the composition of natural gas, it is necessary to take into account changes in spectroscopic characteristics 
in the pressure range of 1-100 atm. We believe that $\rho^{\nu_{1}}$ at any pressure from this range can be estimated using the function presented in Figure 6.

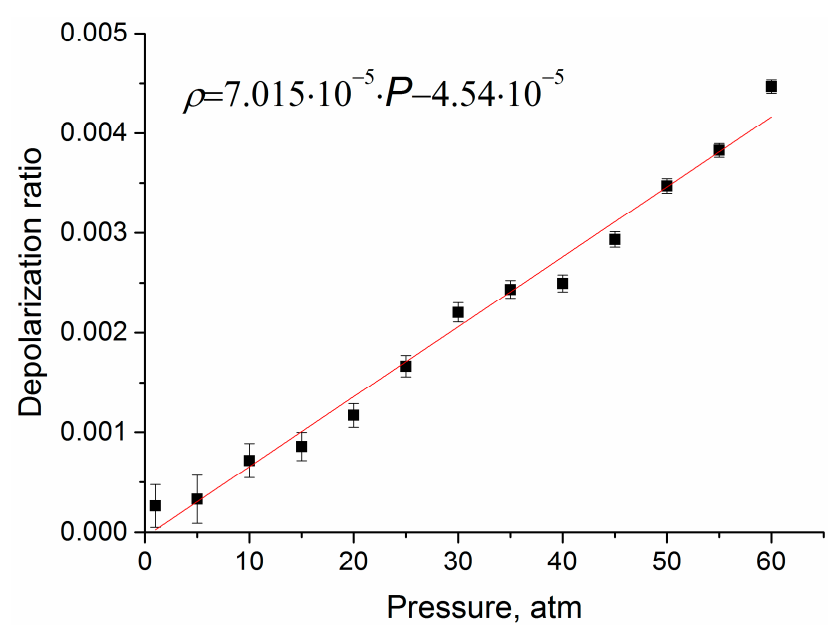

Figure 6. Depolarization ratio of $v_{1}$ band obtained after correction of the intensities to the contribution of the $v_{3}$ lines.

\section{Conclusions}

The performed studies showed that the dependence of depolarization ratios of the $v_{2}$ and $v_{3}$ bands on pressure is negligible. In turn, the degree of depolarization of the $v_{1}$ band increases with pressure and reaches approximately 0.0045 at $60 \mathrm{~atm}$. These data are significantly lower than those published earlier. This is explained by the fact that in our work we used an experimental setup with higher sensitivity, and also took into account the contribution of the lines of the $v_{3}$ band located in the region of $2916-2917 \mathrm{~cm}^{-1}$. We believe that the obtained data on the pressure dependence of the depolarization ratio, as well as changes in the intensities of the polarized and depolarized spectrum of methane, will improve the accuracy of the calculation of methane polarizabilities. These data will be useful in calculating the Raman spectra of methane at different pressures for analysis of natural gas composition using Raman spectroscopy.

Funding: The work was supported by the Russian Science Foundation (RSF), grant No. 19-77-10046.

Conflicts of Interest: The author declares no conflicts of interest.

\section{References}

1. Petrov, D.V.; Matrosov, I.I. Raman Gas Analyzer (RGA): Natural Gas Measurements. Appl. Spectrosc. 2016, 70, 1770-1776. [CrossRef] [PubMed]

2. Petrov, D.V.; Matrosov, I.I.; Tikhomirov, A.A. High-Sensitivity Spontaneous Raman Spectrometer for Gaseous Media. J. Appl. Spectrosc. 2015, 82, 120-124. [CrossRef]

3. Hippler, M. Cavity-Enhanced Raman Spectroscopy of Natural Gas with Optical Feedback cw-Diode Lasers. Anal. Chem. 2015, 87, 7803-7809. [CrossRef] [PubMed]

4. Sandfort, V.; Trabold, B.; Abdolvand, A.; Bolwien, C.; Russell, P.; Wöllenstein, J.; Palzer, S. Monitoring the Wobbe Index of Natural Gas Using Fiber-Enhanced Raman Spectroscopy. Sensors 2017, 17, 2714. [CrossRef] [PubMed]

5. Sieburg, A.; Schneider, S.; Yan, D.; Popp, J.; Frosch, T. Monitoring of gas composition in a laboratory biogas plant using cavity enhanced Raman spectroscopy. Analyst 2018, 143, 1358-1366. [CrossRef]

6. Gao, Y.; Dai, L.-K.; Zhu, H.-D.; Chen, Y.-L.; Zhou, L. Quantitative Analysis of Main Components of Natural Gas Based on Raman Spectroscopy. Chinese J. Anal. Chem. 2019, 47, 67-76. [CrossRef]

7. Gomez Velez, J.; Muller, A. Trace gas sensing using diode-pumped collinearly detected spontaneous Raman scattering enhanced by a multipass cell. Opt. Lett. 2020, 45, 133. [CrossRef] 
8. Sharma, R.; Poonacha, S.; Bekal, A.; Vartak, S.; Weling, A.; Tilak, V.; Mitra, C. Raman analyzer for sensitive natural gas composition analysis. Opt. Eng. 2016, 55, 104103. [CrossRef]

9. Dąbrowski, K.M.; Kuczyński, S.; Barbacki, J.; Włodek, T.; Smulski, R.; Nagy, S. Downhole measurements and determination of natural gas composition using Raman spectroscopy. J. Nat. Gas Sci. Eng. 2019, 65, 25-31. [CrossRef]

10. Lin, F.; Bodnar, R.J.; Becker, S.P. Experimental determination of the Raman $\mathrm{CH}_{4}$ symmetric stretching $\left(v_{1}\right)$ band position from 1-650 bar and $0.3-22{ }^{\circ} \mathrm{C}$ : Application to fluid inclusion studies. Geochim. Cosmochim. Acta 2007, 71, 3746-3756. [CrossRef]

11. Petrov, D.V. Raman Spectrum of Methane in the Range 20-40 ${ }^{\circ}$ C. J. Appl. Spectrosc. 2017, 84, 420-424. [CrossRef]

12. Lin, F.; Sum, A.K.; Bodnar, R.J. Correlation of methane Raman $v 1$ band position with fluid density and interactions at the molecular level. J. Raman Spectrosc. 2007, 38, 1510-1515. [CrossRef]

13. Petrov, D.V. Pressure dependence of peak positions, half widths, and peak intensities of methane Raman bands $\left(v_{2}, 2 v_{4}, v_{1}, v_{3}\right.$, and $\left.2 v_{2}\right)$. J. Raman Spectrosc. 2017, 48, 1426-1431. [CrossRef]

14. Shang, L.; Chou, I.-M.; Burruss, R.C.; Hu, R.; Bi, X. Raman spectroscopic characterization of $\mathrm{CH}_{4}$ density over a wide range of temperature and pressure. J. Raman Spectrosc. 2014, 45, 696-702. [CrossRef]

15. Petrov, D.V. Raman spectrum of methane in nitrogen, carbon dioxide, hydrogen, ethane, and propane environments. Spectrochim. Acta Part A Mol. Biomol. Spectrosc. 2018, 191, 573-578. [CrossRef]

16. Wang, M.; Lu, W.; Li, L.; Qiao, S. Pressure and Temperature Dependence of the Raman Peak Intensity Ratio of Asymmetric Stretching Vibration $\left(v_{3}\right)$ and Asymmetric Bending Overtone $\left(2 v_{2}\right)$ of Methane. Appl. Spectrosc. 2014, 68, 536-540. [CrossRef]

17. Brunsgaard Hansen, S.; Berg, R.W.; Stenby, E.H. How to determine the pressure of a methane-containing gas mixture by means of two weak Raman bands, $v_{3}$ and $2 v_{2}$. J. Raman Spectrosc. 2002, 33, 160-164. [CrossRef]

18. Saito, Y.; Ishibashi, T.; Hamaguchi, H. Polarization-resolved coherent anti-Stokes Raman scattering (CARS) spectroscopy: A new probe of molecular symmetry through accurate determination of the Raman depolarization ratio. J. Raman Spectrosc. 2000, 31, 725-730. [CrossRef]

19. Ikawa, S.; Whalley, E. Effect of pressure on the raman depolarization ratio and the vibrational relaxation of the $\mathrm{v}_{1}$ mode of liquid carbon tetrachloride at $22^{\circ} \mathrm{C}$ and 0-1.1 kbar. Mol. Phys. 1992, 75, 659-667. [CrossRef]

20. Thomas, M.A.; Welsh, H.L. The Raman spectrum of methane. Can. J. Phys. 1960, 38, 1291-1303. [CrossRef]

21. Rose, E.J.; Whitewolf, E.; Baglin, F.G. Isothermal density tuning of the depolarization ratios from the $\mathrm{v}_{1}$ mode of methane. J. Chem. Phys. 1992, 97, 4596-4604. [CrossRef]

22. Wright, M.; Murphy, T.; Baglin, F.G. Isosteric and isothermal studies of the raman depolarization ratios in an argon-methane mixture at $298 \mathrm{~K}$ and $323 \mathrm{~K}$. Mol. Phys. 1994, 82, 277-282. [CrossRef]

23. Petrov, D.V.; Matrosov, I.I.; Sedinkin, D.O.; Zaripov, A.R. Wavenumber calibration of a multichannel Raman spectrometer. Proc. SPIE 2017, 10466, 1046606.

24. Lolck, J.E.; Robiette, A.G. A theoretical model for the interacting upper states of the $v_{1}, v_{3}, 2 v_{2}, v_{2}+v_{4}$, and $2 v_{4}$ bands in methane. J. Mol. Spectrosc. 1981, 88, 14-29. [CrossRef]

25. Dymond, J.H.; Marsh, K.N.; Wilhoit, R.C.; Wong, K.C. Virial Coefficients of Pure Gases and Mixtures; Frenke, M., Marsh, K.N., Eds.; Springer: Berlin, Germany, 2003.

26. Abbate, S.; Gussoni, M.; Zerbi, G. Raman intensities of methanes from electrooptical parameters. J. Mol. Spectrosc. 1978, 73, 415-429. [CrossRef]

(C) 2020 by the author. Licensee MDPI, Basel, Switzerland. This article is an open access article distributed under the terms and conditions of the Creative Commons Attribution (CC BY) license (http://creativecommons.org/licenses/by/4.0/). 